\title{
Review of Limit Equilibrium Methods for Stability Analysis of Dump Slope

\author{
${ }^{*}$ Sumit S Geete, ${ }^{2}$ Hemant K Singh, ${ }^{3}$ Manoj S Tiwari, ${ }^{4}$ Vaishali J Rajurkar \\ ${ }^{1,3,4}$ Shri Ramdeobaba College of Engineering and Management, Nagpur, India \\ ${ }^{2}$ Indian Institute of Technology, Bombay \\ Email: sumit.geete@gmail.com,kumar.h.singh@iitb.ac.in,tiwarims@rknec.edu,rajurkarvj@rknec.edu
}

Received: 22nd October 2019, Accepted: 31st January 2020, Published: 29th February 2020

\begin{abstract}
OBD slope is artificial dump slope. OBD material is excavated material during extraction of the mineral or coal from the earth. Stability analysis of the overburden dump slope is crucial issue in mining industry. Assessment of the factor of safety of OBD slopes on the basis of the limit equilibrium methods are widely used in India. Limit equilibrium methods based on finding path of least resistance offered to sliding of the upper wedge of dump slope. Sliding surface may be circular or non-circular depends on the material of dump slope. Failures of overburden dump slope mostly will be circular. Circular failure occurs, when size of individual particles of fractured OBD will be very much less than overall size of slope. Discontinuities in the OBD slope are source of failure. Discontinuities are connected to each other and results into instability of the OBD slope. In this paper dealt with formulation of various limit equilibrium methods and its application to the calculation of factor of safety of the OBD slope. Overall comparison of limit equilibrium methods was done on the basis of free body diagram of failure surface wedge.
\end{abstract}

\section{Keywords}

Overburden Dump (OBD), Slope Stability, Limit Equilibrium Method (LEM), Factor of safety (FOS)

\section{Introduction}

Requirement of coal for power sector and other industries are increasing day by day. To fulfill this demand, mining activities go deeper and deeper. As depth of mining is increases then stripping ratio also increases rigorously. Huge amount of quantity of excavated material which is called as spoil is generated. This excavated material store in the form of waste dump or spoil dump also called as overburden dump. Dumps are again classified as internal dump (dump located inside the mine itself) and external dump (dump located nearby area of mine). Excavated waste material mainly consists of mixture of fragmented or fractured rock mass and soil. Main problem of dumping this waste material is stability. From past accidents, it is assume that stability of the dump become prime concerned. Dump should be design safely for long term stability with economical way. In Indian mining industries, external dumping preferred over internal dumping. By designing the dump slope in such a way that it should accommodate large capacity waste dump material. As slope angle of dump increased then dump waste volume carrying also increases but at the same time chances of failure of dump also increases. Design of overburden dump is depend on the geotechnical parameters of fractured rock mass and soil.[4] Overburden dumps are large man made slope constructed but with less attention to the analysis, design and implementation. As lack of attention for the designing of these dump results into the uneconomical and unsafe slope. Vibrations and blasting are disturbing forces for dump stability. Seismic forces cause the displacement of large mass of overburden and failure.

\section{Observed Failure Mode and Failure Mechanism}

Caldwell and Moss (1981) [3] mentioned various types of mine waste dump failure. Surface slide, shallow flow slide, base failure, block translation, Base failure and foundation circular failure. Analysis of overburden dump is complex in nature as its involve self weight of dump, heterogeneity of material (fractured rock to soil), geotechnical properties of dump material, strength of foundation over which dump crated, seepage pressure, tension cracks etc. Analytical techniques available are cumbersome to use. Mostly design of dump done on the basis of past experience. Rate of deformation and change of rate of deformation are good indicator for monitoring of the dump slope. Dump slope depend on the seepage i.e. pore pressure. Seepage is depends on the rainfall, porosity of the dump material and discontinuities. Location of ground water table i.e. phreatic line is most essential part of analysis of dump slope. Area of dump slope below the phreatic line is under pore pressure and due to this pore pressure effective strength of dump material reduces.[2] Again, water percolating through the overburden dump causes the erosion of dump material which results in to the dump failure. [12] Hence presence of ground water table in the overburden dump increases the driving force. Seismic or vibrations forces are induces the high inertial forces in the dump slope mass. Due do this vibrations forces the factor of safety reduces drastically and chances of failure of the dump slope increases. Earthquake load persist for very short period of time i.e. factor of safety reduces very short period of time. Overall effect of dump slope is accumulating the displacement caused by earthquake forces. 


\section{Factor affecting the Slope Stability [11]}

1. Foundation soil - Nature of the foundation soil affect the stability of the slope. If the soft clay is present below the dump then chances of failure may increased.

2. Dump height - as dump height increase then factor of safety of the dump slope decreases.

3. Dump material - geotechnical properties of the dump material affect the porosity, cohesion, angle of internal friction, seepage condition etc.

4. Rainfall - this is most important factor that controlled the percolation of water from the dump. Seasonal variation in the ground water table will affect the stability of the slope.

Basically study of the failure mechanism of the fractured rock mass or soil is not done scientifically. Hence various combinations of configurations of the dump material are done which leads failure. Therefore following conditions are needs to studies

1. Conditions of occurrence of the types of failure mechanism

2. Conditions of failure initiation

3. Shape and location of the failure surface

4. Effect of dump slope geometry on failure mechanism

\section{Objective of Slope Stability of Overburden Dump}

1. To design the safe slope with given geotechnical properties of dump material and field constraints.

2. To find out the stability of existing dump from various methods of stability analysis.

3. To check the possibility of enhancement of capacity of existing dump.

4. To improved the stability of existing dump through reinforcement measures.

Design Parameters of Dump Slope [9]

\begin{tabular}{|l|l|l|l|}
\hline Dump foundations properties & $\begin{array}{l}\text { Geotechnical properties } \\
\text { of dump material }\end{array}$ & $\begin{array}{l}\text { Plasticity of dump } \\
\text { material }\end{array}$ & Floor inclination \\
\hline Bench width of dump & Bench height & Slope angle & Overall height of dump \\
\hline $\begin{array}{l}\text { Reduction of strength of dump material near the vicinity of } \\
\text { the floor. }\end{array}$ & $\begin{array}{l}\text { Strain development } \\
\text { in dump }\end{array}$ & Construction sequence \\
\hline
\end{tabular}

Factors for failure of OBD Slope [9]

\begin{tabular}{|l|l|l|l|}
\hline $\begin{array}{l}\text { Gravity force of OBD } \\
\text { material }\end{array}$ & Seepage forces & $\begin{array}{l}\text { Degradations of the } \\
\text { OBD slope material over } \\
\text { a period of time }\end{array}$ & $\begin{array}{l}\text { Vibrations (Earthquake, } \\
\text { blasting, vehicular } \\
\text { movement etc.) }\end{array}$ \\
\hline
\end{tabular}

Types of failure Mode [6][13]

1) Slope failure

a) Face Failure

b) Toe Failure

2) Base failure

3) Wedge failure

4) Composite failure 


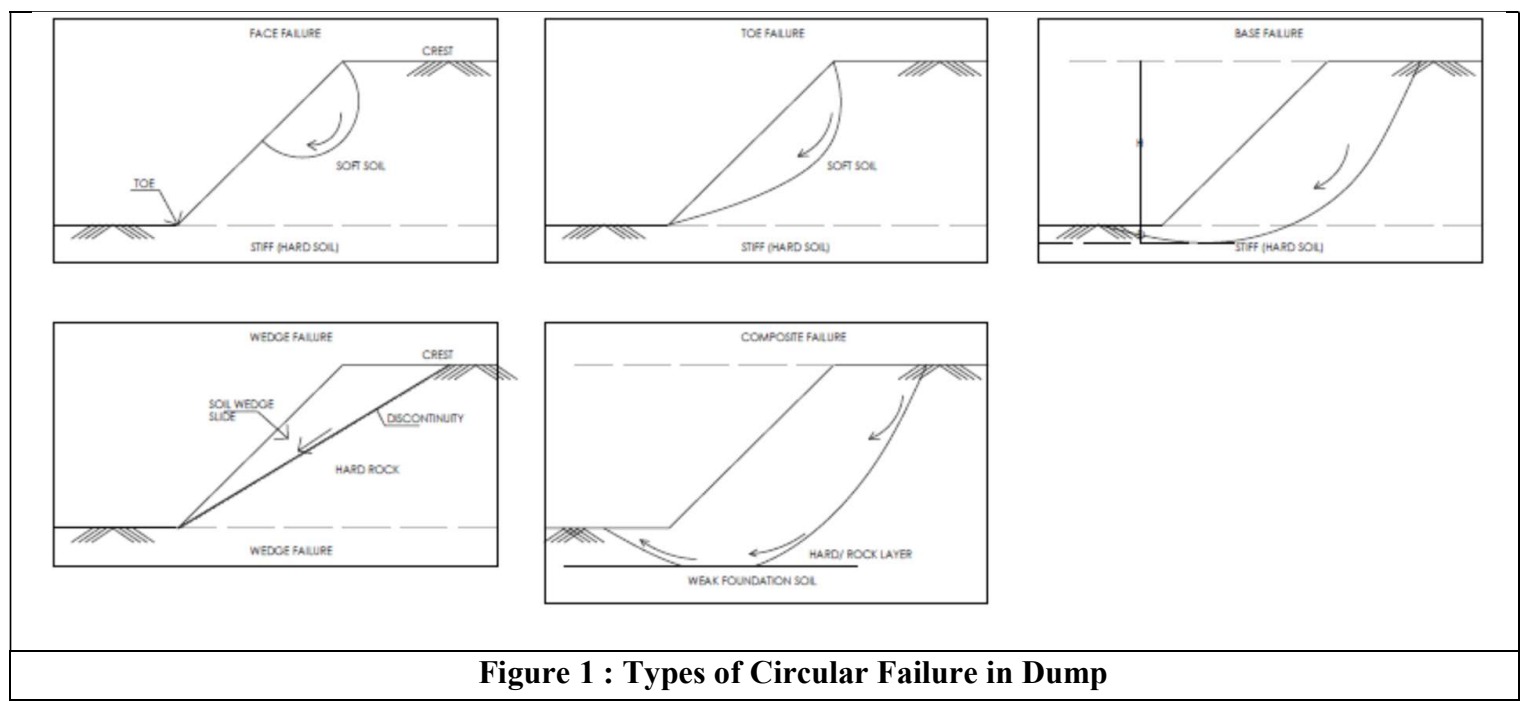

Stability Analysis Procedure

Limit equilibrium method is used for the stability analysis of circular failure. In this procedure slope is divided into number of vertical slices and equilibrium analysis of individual slice is evaluated. The number equations of equilibrium available depend on number of slice $(\mathrm{N})$ and number of equilibrium conditions that are used. The number equation available for force equilibrium is $2 \mathrm{~N}$. Number of equilibrium equations available if force and moment taken into consideration of analysis is $3 \mathrm{~N}$. Number of unknown if only force equilibrium consider is $(3 \mathrm{~N}-1)$ and $(5 \mathrm{~N}-1)$ if force and moment equations of equilibrium are considered. For realistic analysis, slope is divided into 10 to 40 numbers of slices. This analysis is statically indeterminate and hence, assumptions will require creating extra equations to evaluate all unknown parameters.

$$
F S=\frac{\text { Shear Strength available to resist sliding }(c+\sigma \tan \phi)}{\text { Shear stress required for equilibrium on the slip surface }\left(\tau_{f}\right)}
$$

\section{Common Methods of Stability Analysis}

The various methods are differ slightly from each other based on number of forces consider on slice but based on limit equilibrium method.

1) Stability of slope in $c_{u}$ and $\phi_{u}=0$

2) Swedish Circle method / Slip Circle method / Fellenius method / Slices method (1936)

3) Bishops's Simplified Method (1955)

4) Janbu's Method (1954)

5) Janbu's Corrected method (1973)

6) Morgenstern and Price's Method (1965)

7) Spencer's Method (1967)

8) Huang's Method (1980)

9) Stability Chart Method

\section{Limit Equilibrium Analysis [14]}

In this analysis we are equating the driving forces with resisting forces. Driving forces (Shearing forces) resulted from gravity forces and internal pressures acting on a mass bounded by failure surface. Gravity force is a function of weight of the block which likely to be failed, slope angle, depth of failure surface and some cases slope height. Pressure developed in the discontinuities of intact rock masses from water, freezing, swelling materials etc. and in case of fractured rock or soil, development of pressure due to presence of water in tension cracks. Resisting forces are provided by the shear strength along failure surface, and it is decreases as pore water pressure increases or by leaching of cementing constituents of slope material. Active and passive stresses are acting on a slope. The passive resistance at the lower portions is most significant. 
1. Stability of Slope in $c_{u}$ and $\phi_{u}=0$ [17]

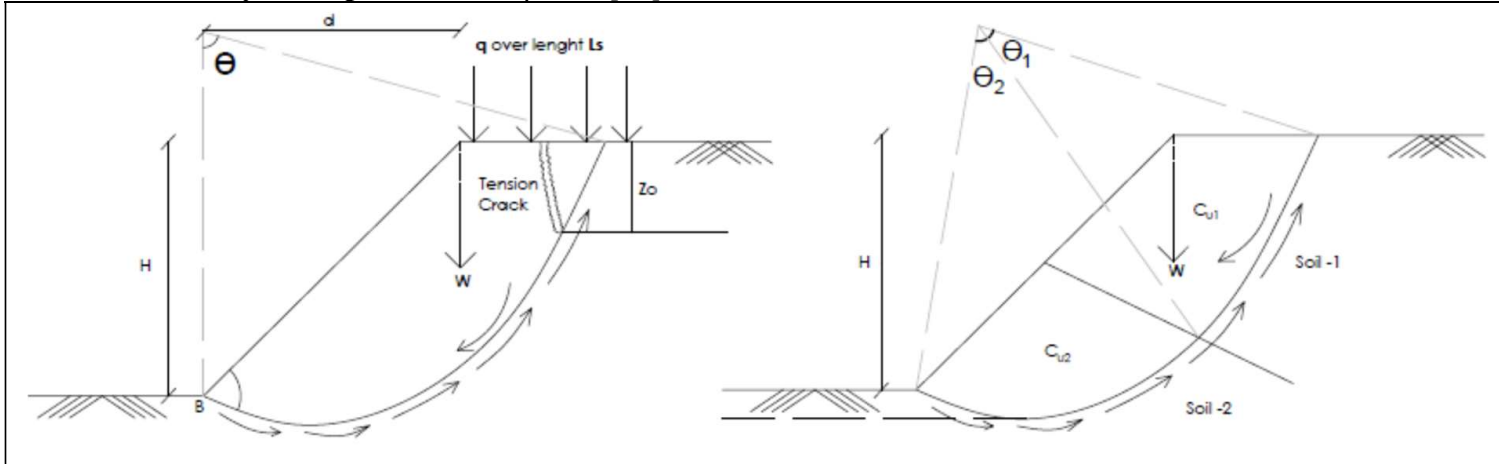

Figure 2: Slope in $\mathrm{c}_{\mathrm{u}}$ and $\phi_{\mathrm{u}}=0$

$$
\begin{gathered}
W x d-\int_{o}^{\theta} d l x c_{u} x R=0 \\
W x d-\frac{c_{u} R}{F} \int_{o}^{\theta} d l=0 \\
W x d-\frac{c_{u} R^{2} \theta}{F}=0 \\
F=\frac{c_{u} R^{2} \theta}{W d} \\
F=\frac{c_{u} L_{a} R}{W d}
\end{gathered}
$$

$\mathrm{q}$ is a surcharge loading applied over the length of Ls

$$
F=\frac{c_{u} R^{2} \theta}{W d+q L_{s}}
$$

If soil is composed of two different layers as indicated in the Fig 2, then

$$
F=\frac{R^{2}\left(c_{u 1} \theta_{1}^{\prime}+c_{u 2} \theta_{2}^{\prime}\right)}{W d+q L_{s}}
$$

\section{Swedish Circle Method / Slip Circle Method / Fellenius Method / Slices Method [5][7]}

Fellenius published a method of slices based on cylindrical failure Surface which Slip Circle method / Fellenius method. This method is modified for effective stresses (considering pore pressure) called as Ordinary method of slices. Assumptions

1. Slip surface assumed as an arc of a circle.

2. Method based on total stress analysis can be extended for effective stress analysis.

3. It is for homogeneous, isotropic mass without seepage.

4. Minimum factor of safety decided by trials.

5. Wedge divided into number of slices.

6. Interslice forces may or may not be accounted.

7. Both total stress as well as effective stress analysis can be done.

8. Method can be applicable to
a. Homogeneous soil
b. Stratified soil
c. Saturated, semi-saturated, submerge soil masses with or without seepage
d. Uniform / Non uniform slopes 


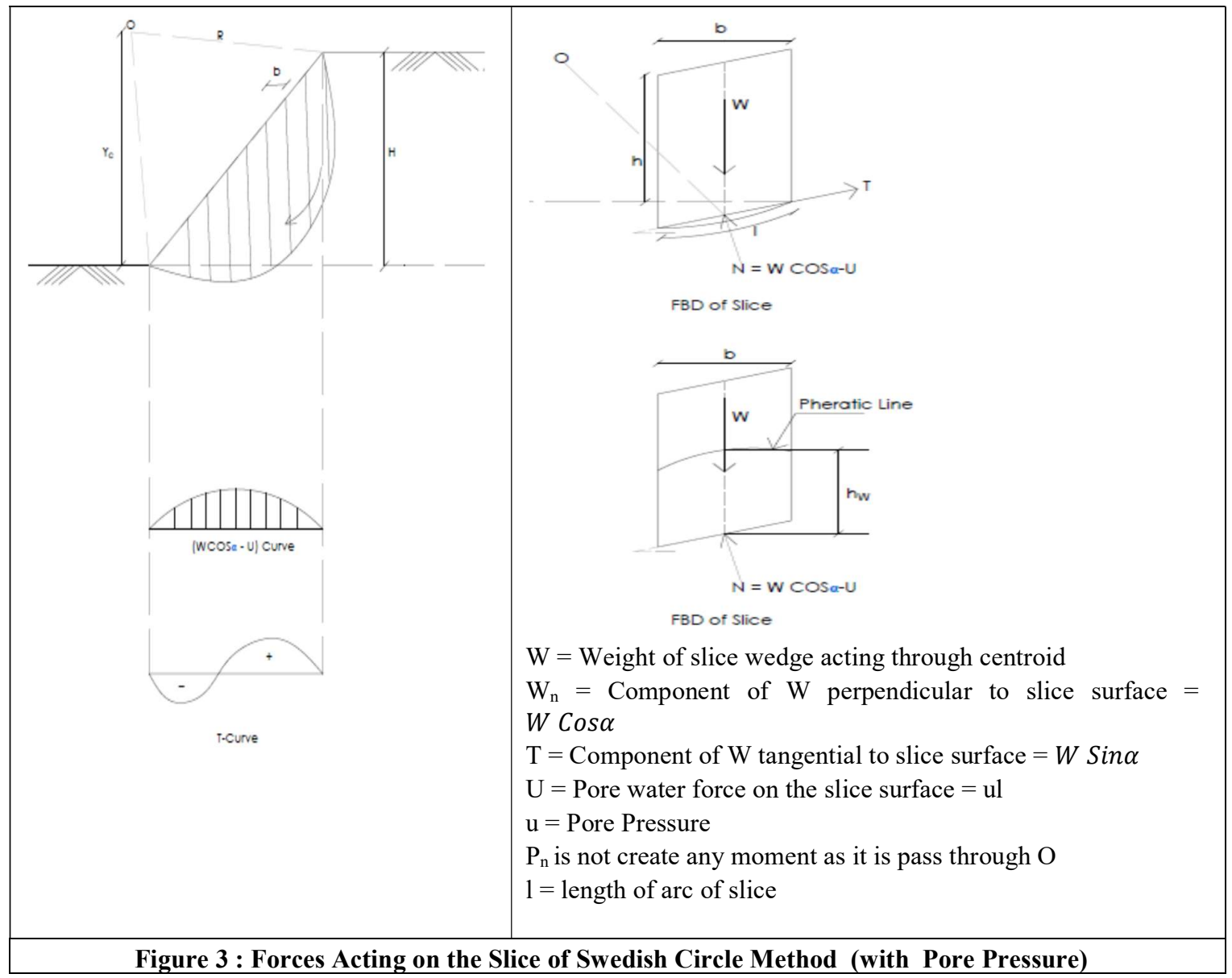

$\mathrm{M}_{\mathrm{D}}=$ Driving Moment $@ \mathrm{O}=\mathrm{r} \Sigma \mathrm{T}$

$\mathrm{M}_{\mathrm{R}}=$ Resisting Moment $@ \mathrm{O}=\Sigma r\left[c^{\prime} l+(W n-U) \tan \phi^{\prime}\right]$

$$
\begin{gathered}
f o s=\frac{M R}{M D} \\
\text { fos }=\frac{\Sigma\left[c^{\prime} l+(W n-) \tan \phi^{\prime}\right]}{\Sigma T} \\
\text { fos }=\frac{\Sigma\left[c^{\prime} l+(W \cos \alpha) \tan \phi^{\prime}\right]}{\Sigma W \sin \alpha}
\end{gathered}
$$

For dimensionless term $r_{u}=\frac{u b}{w}=u b / \gamma b h$

$$
=\frac{\gamma_{w} h_{w}}{\gamma h}
$$

$\mathrm{h}_{\mathrm{w}}$ is obtained at mid height of slice with flow net.

$$
\begin{gathered}
f o s=\frac{\sum\left[c^{\prime} l+(w \cos \alpha-u l) \tan \phi^{\prime}\right]}{\Sigma W \sin \alpha} \\
f o s=\frac{\Sigma\left[c^{\prime} l+w\left(\cos \alpha-r_{u} \sec \alpha\right) \tan \phi^{\prime}\right]}{\Sigma W \sin \alpha}
\end{gathered}
$$


Bishops's Simplified Method[1][2]

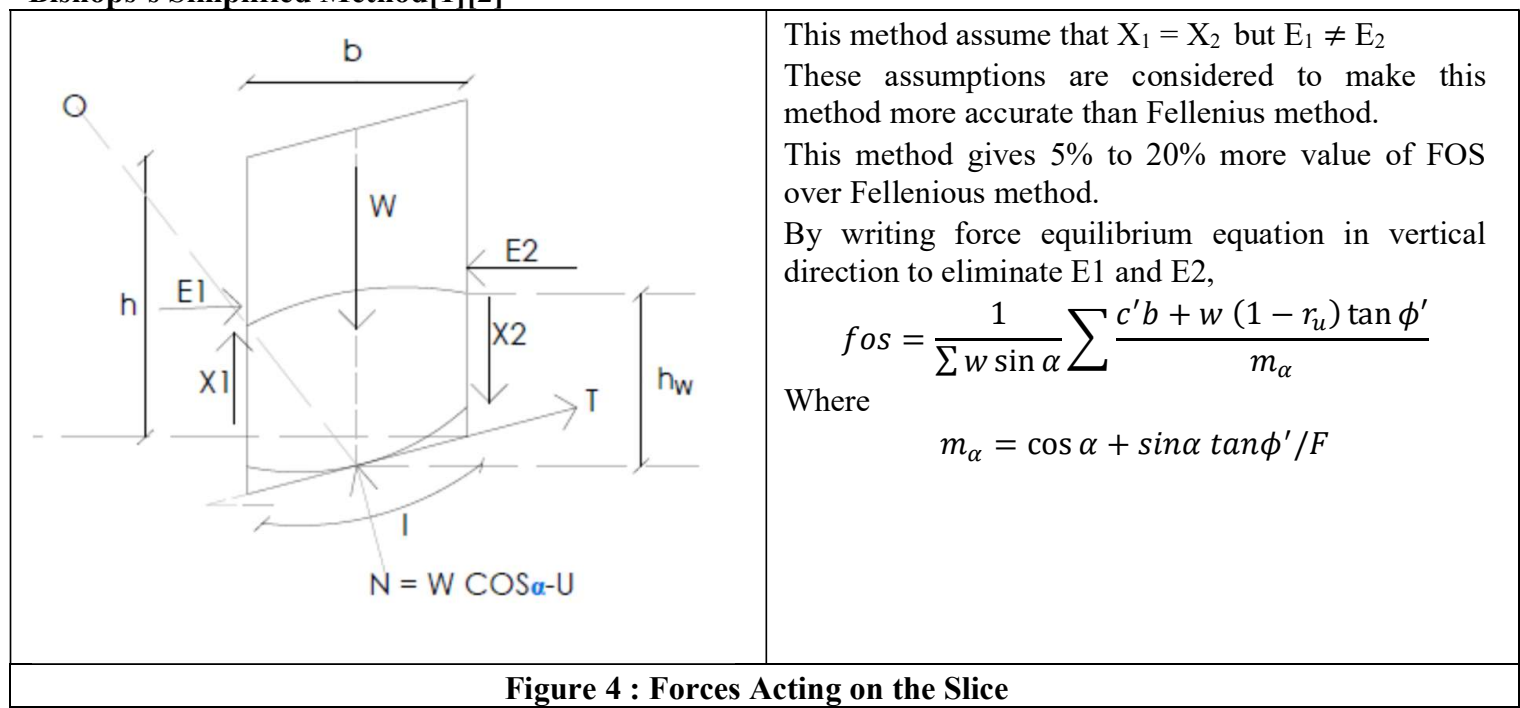

In this method, initial value of FOS is assumed (slightly greater than FOS of Fellenius method) and substitute in the equation to obtained new FOS. This process of iteration is repeated until assumed FOS and calculated FOS nearly equal. Only 3-4 trial are required to get the appropriate lowest value of FOS and process is rapid.

Bishop's also show that E1-E2 $\neq 0$ of resultant has only marginal effect on FOS.

Janbu's Method [8]

In this method applicable to any shape of failure surface. This analysis is based on slice method. All equilibrium conditions are fully satisfied. This method is similar to Bishop's simplified method, a minimum FOS is obtained for critical non-circular failure surface. This method required more computational efforts Janbu's General Equation for FOS is as below

$$
f o s=\frac{1}{\sum w \tan \alpha} \sum \frac{c^{\prime} b+(w-u b+\Delta X) \tan \phi^{\prime}}{m_{\alpha_{j}}}
$$

Where

$$
m_{\alpha_{j}}=\cos ^{2} \alpha\left[1+\frac{\tan \alpha \tan \phi^{\prime}}{F}\right]
$$

A method is suitable for routine applications which based on neglecting $\Delta X$ term and increasing the number of slices. To simplify the calculations, the sliding mass divided into blocks and then each block is divided into number of slices. The angle $\alpha$ is same for all slices but different pore pressure in particular block. Application of routine method will cause the reduction in factor of safety corresponding to the critical surface. Therefore Janbu's proposed increased in factor of safety as per the for $c^{\prime}=0, c^{\prime}-\phi$ type of soil and $\phi=0$ which is based on the ratio of $\mathrm{d} / \mathrm{L}$.

$\mathrm{L}=$ length of $\mathrm{AE}$

$\mathrm{d}=$ maximum distance of non- circular failure surface from line AE.

Increased factor of safety given as

$$
\begin{array}{r}
\text { fos }_{\text {corrected }}=f_{0} \cdot \text { fos }_{\text {before correction }} \\
f_{0}=1+K\left[\frac{d}{L}-1.4 \frac{d^{2}}{L}\right]
\end{array}
$$

For

$$
\begin{array}{llr}
c^{\prime}=0 & \text { Then } & \mathrm{K}=0.31 \\
c^{\prime}>0 \text { and } \phi^{\prime}>0 & \text { Then } & \mathrm{K}=0.5
\end{array}
$$

\section{Janbu's Corrected Method [8]}

1. This method also called as Junbu's modified method of slice / Janbu's generalized method of slice (GPS).

2. It handles complicated geometry and failure surface.

3. Consider interslice forces and assume line of action thrust for interslice forces. 
4. It's satisfied both force and moment equations.

5. This method satisfied all conditions of equilibrium of moment for slice - vertical force and horizontal force, moment equilibrium of whole sliding mass except the last slide.

6. Interslice forces may be calculated by considering moment about centre of base of slice.

7. Thrust line it is line of location of interslice forces acts therefore problem become statically determinate.

8. PGS, line of thrust defined as, the line joining the points of application of resultant of interslice forces in respect of all slides.

9. As per Janbu's (1957) and Spencer (1973), line of thrust lies between $1 / 3^{\text {rd }}$ to $2 / 3^{\text {rd }}$ of the slice height from the base in active and passive condition respective (Aryal, 2008).

$$
\begin{gathered}
f o s_{m}=\frac{\sum\left\{c^{\prime} l+(N-u l) \tan \phi^{\prime}\right\}}{\sum w \sin \alpha} \\
\operatorname{fos}_{f}=\frac{\sum\left\{c^{\prime} l+(N-u l) \tan \phi^{\prime}\right\} \sec \alpha}{\sum\{w-(X 2-X 1)\} \tan \alpha+\sum(E 2-E 1)}
\end{gathered}
$$

Total base Normal force acting on shear surface is a function of interslice shear force.

$$
N=\frac{\left\{w-(X 2-X 1)-\frac{\left(c^{\prime} l-u l \tan \phi^{\prime}\right) \sin \alpha}{F}\right\}}{m_{\alpha}}
$$

\section{Morgenstern and Price's Method [10]}

1. Sliding mass divided into the vertical slices.

2. Failure surface is non-circular

Equilibrium of vertical element of width $d x$ within the each slice is then investigated by introducing five functions as follows

1. $\mathrm{Y}=\mathrm{s}(\mathrm{x})$ defines shape of the slope and its boundary (its linear equation)

2. $\mathrm{Y}=\mathrm{y}(\mathrm{x})$ represents failure surface (for each slice linear equation is assumed)

3. $\mathrm{Y}=\mathrm{h}(\mathrm{x})$ defines the line of action of forces due to water pressure

4. $Y=y^{\prime}(x)$ defines of line of action of effective normal force $E^{\prime}$ acting on vertical side.

5. $X=\lambda f(x) E$ ' defines the line of action of shear stress to $X$ and effective normal force $E$ '

Force equilibrium equations constructed parallel and normal to the direction to the sliding surface, are combined with an application of Mohr-Coulmb failure criteria on the failure plane to yield following equations.

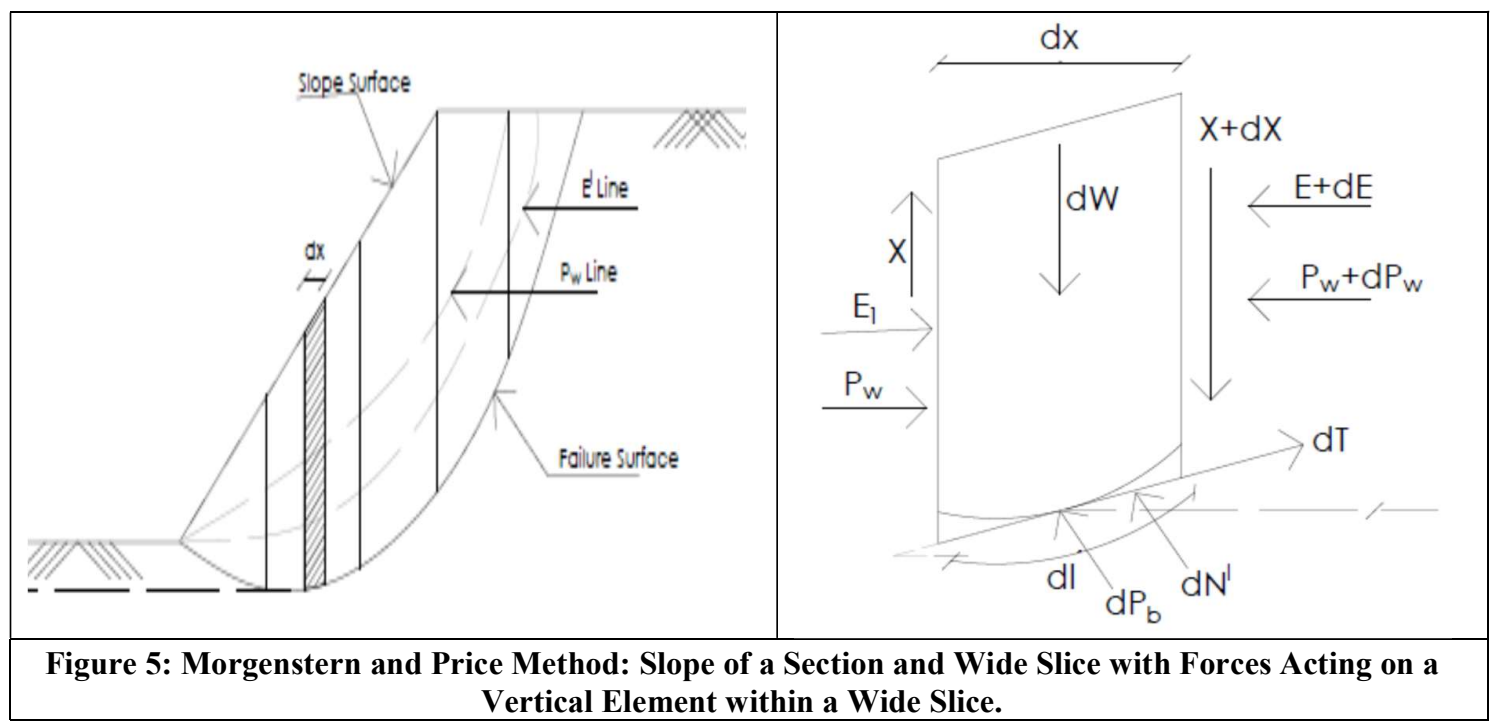




$$
\begin{gathered}
\frac{c^{\prime}}{F} \sec ^{2} \alpha-\frac{\tan \phi^{\prime}}{F}\left[\tan \alpha \frac{d E^{\prime}}{d x}+\tan \alpha \frac{d P_{W}}{d x}+\frac{d X}{d x}-\frac{d W}{d x}+\sec \alpha \frac{d P_{b}}{d x}\right. \\
=\frac{d E^{\prime}}{d x}+\frac{d P_{W}}{d x}-\tan \alpha \frac{d X}{d x}+\tan \alpha \frac{d W}{d x}
\end{gathered}
$$

For convenience moment equilibrium is considered at the midpoint of the base of the element and yields the following differential equations

$$
y\left(\frac{d E^{\prime}}{d x}+\frac{d P_{w}}{d x}\right)-\left[\frac{d\left(E^{\prime y^{\prime}}{ }^{\prime}\right)}{d x}+\frac{d\left(P_{w} h\right)}{d x}\right]+X=0
$$

The difficulties in the solving these two differential equations may be overcome by considering the linear equations for all five elements within the integration limit of slice.

In above equations

$\lambda$ is scale factor and determined within the solution.

$\mathrm{Pw}$ is the water pressure acting on the vertical plane of each slice.

Spencer's Method [15][16]

1. This analysis is based on slice method.

2. This analysis is applicable to failure surface of any shape.

3. This analysis satisfied all conditions of equilibrium

The interslice forces E1, E2, X1 and X2 are replaced by single force Z with its point of application on the centre line of the slice and making angle $\Theta$ with horizontal. In general formulation it's assume that direction of $\mathrm{Z}$ is opposite to the direction of $\mathrm{T}$. Vertical and horizontal force equilibrium equations are combined to eliminate N' and gives following equation

$$
Z=\frac{\left(\frac{c^{\prime} l}{F}\right)+\frac{(W \cos \alpha-u l) \tan \phi^{\prime}}{F}-W \sin \alpha}{\operatorname{Cos}(\alpha-\theta)\left[1+\frac{\tan (\alpha-\theta) \tan \theta^{\prime}}{F}\right]}
$$

Again

$$
\Delta X=Z \sin \theta
$$$$
\Delta E=Z \cos \theta
$$

And

$\sum Z \sin \theta=0 \quad \sum Z \cos \theta=0$

Moment of rotation about centre of rotation is zero

$$
\sum Z \cos (\alpha-\theta)=0
$$

\section{Results and Discussion}

1. Bishops's Simplified Method gives $5 \%$ to $20 \%$ more value of FOS over Fellenius method. In Bishops's Simplified Method is assumed equilibrium of vertical forces between slices.

2. Janbu's Method In this method applicable to any shape of failure surface. This method is similar to Bishop's simplified method, a minimum FOS is obtained for critical non-circular failure surface.

3. Janbu's Corrected methods consider interslice forces and assume line of action thrust for interslice forces. This method satisfied all conditions of equilibrium of moment for slice - vertical force and horizontal force, moment equilibrium of whole sliding mass except the last slide.

4. Morgenstern and Price's Method Sliding mass divided into the vertical slices. Failure surface is noncircular.

5. Spencer's Method analysis is based on slice method. This analysis is applicable to failure surface of any shape. This analysis satisfied all conditions of equilibrium

\section{Conclusion}

In this procedure slope is divided into number of vertical slices and equilibrium analysis of individual slice is evaluated. In this analysis we are equating the driving forces with resisting forces. Driving forces (Shearing forces) resulted from gravity forces and internal pressures acting on a mass bounded by failure surface. Gravity force is a function of weight of the block which likely to be failed, slope angle, depth of failure surface and some cases slope height. Pressure developed in the discontinuities of intact rock masses from water, freezing, swelling materials etc. and in case of fractured rock or soil, development of pressure due to presence of water in tension cracks. Resisting forces are provided by the shear strength along failure surface, and it is decreases as 
pore water pressure increases or by leaching of cementing constituents of slope material. Active and passive stresses are acting on a slope.

\section{References}

1. Bishop, A.W. (1995) The use of slip circle in the stability analysis of earth slope. Geotechnique,5, 7-17

2. Bishop, A.W. 1959. The principle of effective stress. Tek. Ukebl. 106:859-863.

3. Caldwell, J. A. and Moss, A.S.E. 1981. The Simplified Analysis of Mine Waste Embankments. Symposium on Design of Non-Impounding Mine Waste Embankments. Denver USA. AIME Fall Meeting 1981.

4. Chakravarty, Radhakanta Koner and Debashish. 2010. "Stability Study of The Mine Overburden Dumps Slope : A Micromechanical Approach.” XXXII(1).

5. Fellenius, W. - Calculation of the Stability of Earth Damsll. Proceedings of the Second Congress of Large Dams, 4, pp. 445-463, 1936

6. Geotechnical Engineering Investigation Handbook Roy E Hunt, Second Edition, CRC Press, Taylor \& Francis Group, plc, London, UK.

7. Geotechnical Enginnering : Principles and Practices Donald P Coduto (1998).

8. Janbu, N (1954) Application of composite slide circles for stability analysis. Proc. European Conference on stability of Earth Slope. Stockholm, 3, pp. 43-9.

9. Kainthola, A., Verma, D., Gupte, S.S., Singh, T. N. - Analysis Of Failed Dump Slope Using Limit Equilibrium Approach\|, Mini. Engg. Jour. 12 (12), pp. 28-32, 2011.

10. Mongenstern, N.R. and Price, V.E. (1965) The Analysis of stability of general slide surfaces. Geotechnique, 15, 79-93.

11. O.P. Upadhyay, D.K. Sharma \& D.P. Singh (1990) Factors affecting stability of waste dumps in mines, International Journal of Surface Mining, Reclamation and Environment, 4:3, 95-99, DOI: 10.1080/09208119008944174.

12. Rahardjo H, Leong EC, Rezaur RB (2008) Effect of antecedent rainfall on pore-water pressure distribution characteristics in residual soil slopes under tropical rainfall. Hydrol Process 22:506-523. doi:10.1002/hyp.6880.

13. Rock Slope Engineering, Duncan C Wyllie and C W Mah, $4^{\text {th }}$ Edition, Based on $3^{\text {rd }}$ Edition by E Hoek and J Bray, Spon Press, Taylor \& Francis Group, plc, New York.

14. Soil Mechanics: Basic Concept and Engineering Application, A. Aysen, Paperback Edition, Taylor \& Francis Group, plc, London, UK.

15. Spencer, E, (1969) Circular and Logarithmic spiral slide surface. J. Soil mech. Foundation Div. ASCE. 95 (SM 1), 227-234.

16. Spencer, E. (1967) A method of analysis of the stability of embankments assuming parallel inter-slice forces. Geotechnique, 17, 11-26.

17. Taylor, D.W. (1937) Stability of earth slopes. J. Boston Soc. Civil Engineers, 24, 197 pages. 